\title{
Survei efektivitas pembelajaran teknik start jongkok pada materi lari jarak pendek
}

\section{Survey on the effectiveness of learning the crouching start technique on short distance running learning}

\section{Samsul Arifin*,1, Taufik Rahman', Abdul Azis ${ }^{1}$}

${ }^{1}$ Pendidikan Jasmani, Kesehatan, dan Rekreasi, STKIP PGRI Sumenep, Indonesia ${ }^{*}$ Corresponding Author

\begin{abstract}
Abstrak
Tujuan penelitian ini adalah untuk menginvestigasi pelaksanaan pembelajaran pendidikan jasmani yang dilakukan secara online di SDN Gayam II yang berada di Kepulauan Sapudi, Kabupaten Sumenep. Data penelitian diperoleh dari hasil wawancara dengan guru pendidikan jasmani, peserta didik, dan orang tua, serta hasil observasi langsung yang dilakukan oleh peneliti. Hasil penelitian menunjukkan bahwa: 1) kendala pada jaringan internet yang kurang bagus di Kepulauan Sapudi; 2) kendala perekonomian yang rendah, hal ini menyebabkan tidak semua peserta didik dan wali murid mempunyai handphone (HP) android; dan 3) ada sebagian orang tua yang tidak bisa membantu mengawasi pembelajaran online. Sehingga dapat disimpulkan bahwa pembelajaran pendidikan di SDN Gayam II Kepulauan Sapudi, Kabupaten Sumenep kurang bahkan cenderung tidak efektif untuk diterapkan.
\end{abstract}

Kata Kunci: efektivitas; pembelajaran; online; pendidikan jasmani; pandemi; Covid-19.

\begin{abstract}
The purpose of this study was to investigate the implementation of online physical education learning at SDN Gayam II in the Sapudi Islands, Sumenep Regency. The research data was obtained from the results of interviews with physical education teachers, students, and parents, as well as the results of direct observations made by researchers. The results showed that: 1) the problems with the internet network were not good in the Sapudi Islands; 2) low economic constraints, this causes not all students and guardians of students to have android mobile phones (HP); and 3) there are some parents who cannot help supervise online learning. So it can be concluded that educational learning at SDN Gayam II Sapudi Islands, Sumenep Regency is less and even tends to be ineffective.
\end{abstract}

Keywords: effectiveness; learning; online; physical education; pandemic; Covid-19.

Received: 9 Oktober 2021; Revised: 15 October 2021; Accepted: 19 October 2021

Corresponding author: Samsul Arifin, J1. Trunojoyo, Sumenep, 69417, Jawa Timur Email: samsul.arifin@stkippgrisumenep.ac.id

\section{PENDAHULUAN}

Pendidikan jasmani pada hakikatnya adalah proses pendidikan yang memanfaatkan aktivitas fisik untuk menghasilkan perubahan holistik dalam kualitas individu, baik dalam hal fisik, mental, serta emosional. 
Berdasarkan isi dari undang-undang RI No. 20 Tahun 2003 pendidikan jasmani mempunyai peranan penting dalam pembentukan manusia seutuhnya. Pendidikan jasmani olahraga dan kesehatan merupakan bagian integral dari pendidikan secara keseluruhan, bertujuan untuk mengembangkan aspek kebugaran jasmani, keterampilan gerak, keterampilan berfikir kritis, keterampilan sosial, penalaran, stabilitas emosional, tindakan moral, aspek pola hidup sehat, dan pengenalan lingkungan bersih melalui aktivitas pendidikan jasmani, olahraga dan kesehatan terpilih dan direncanakan secara sistematis dalam rangka mencapai tujuan pendidikan nasional (Walton-Fisette $\&$ Wuest, 2015).

Pada masa pandemi Covid-19 banyak satuan pendidikan melakukan proses pembelajaran secara online. Salah satunya adalah SDN Gayam II yang sudah menerapkan pembelajaran jarak jauh (PJJ). Hal tersebut karena akses jaringan di Kepulaan Sapudi sudah tersedia dan dapat digunakan dalam proses pembelajaran online. Mata pelajaran pendidikan jasmani di SDN Gayam II diterapkan melalui secara online menggunakan aplikasi whatsApp atau online, tetapi pelaksanaannya tidak semudah yang dibayangkan. Banyak hal yang dipikirkan dan dipertimbangkan demi tercapainya tujuan pembelajaran yang telag direncanakan sebelumnya, dan juga guru pendidikan jasmani harus mengubah strategi pembelajaran, metode, model, bahkan memikirkan ketersediaan fasilitas penunjuang pembelajaran online tersebut, seperti handphone atau komputer jinjing (laptop). Kondisi yang terjadi di SDN Gayam II tahun pelajaran 2020/2021 dimasa pandemi Covid-19 peserta didik diharapkan mampu mengikuti pembelajaran teknik melakukan start jongkok pada materi lari sprint melalui online atau online dengan baik dan harus ada daya dukung partisipasi anak, orang tua, peralatan HP, pulsa, dan buku paket, namun tidak semua peserta didik bisa mengikuti pembelajaran dikarenakan masalah ada sebagian peserta didik yang belom mempunyai HP android karena faktor ekonomi sehingga pembelajaran belum maksimal dan pembelajaran online hanya di lakukan lewat WhatsApp. Penelitian di bidang pendidikan online dan jarak jauh telah memberikan wawasan tentang kualitas dinamis dari pengajaran dan pembelajaran di lingkungan online 
Samsul Arifin, Taufik Rahman, Abdul Azis

(Barbour, 2010). Secara khusus, para praktisi pendidikan telah menganjurkan praktik pedagogis dalam pembelajaran online yang berfokus pada pendekatan konstruktivis yang berpusat pada peserta didik yang mempromosikan lingkungan interaktif dan pengalaman belajar yang relevan/otentik (Beldarrain, 2008).

Mustofa et al., (2019) pembelajaran online merupakan sebuah inovasi pendidikan yang melibatkan unsur teknologi informasi dalam pembelajaran sistem pendidikan jarak jauh dengan sekumpulan metode pengajaran yang terdapat aktivitas pengajaran yang dilaksanakan secara terpisah dari aktivitas belajar pembelajaran online diselenggarakan melalui jaringan internet dan website artinya bahwa penggunaan pembelajaran online melibatkan unsur teknologi sebagai sarana dan jaringan internet sebagai sistem.

Penelitian terbaru tentang pembelajaran online dalam pendidikan jasmani telah memberikan informasi tentang faktor-faktor pembelajaran seperti persepsi peserta didik dan guru, peningkatan kognitif dan kebugaran peserta didik yang terlibat dalam pembelajaran online, strategi dan metode pembelajaran untuk menyediakan pembelajaran online (Daum \& Buschner, 2014; Goad et al., 2021). (Daum, 2020) melakukan penelitian dengan 912 guru pendidikan jasmani yang mengajar secara online $(N=32)$ untuk menyelidiki konten pembelajaran, desain pelajaran, dan metode pengajaran di sekolah menengah. Temuan utama menunjukkan kurangnya perkembangan motorik dan partisipasi peserta didik yang terbatas, dengan kurang dari 30\% guru melaporkan menyelesaikan 225 menit pendidikan jasmani yang direkomendasikan. Dan pembelajaran campuran, yang menggabungkan pembelajaran online dan tradisional (tatap muka), juga ditemukan menghasilkan persepsi positif pada peserta didik sekolah menengah (Williams et al., 2020).

Berkaitan dengan hal tersbut, maka tujuan penelitian ini adalah untuk meenginvestigasi pelaksanaan pembelajaran pendidikan jasmani yang dilakukan secara online di SDN Gayam II yang berada di Kepulauan Sapudi, Kabupaten Sumenep. Serta menginventarisir kendala yang dialami oleh 
Samsul Arifin, Taufik Rahman, Abdul Azis

guru, peserta didik, dan orang tua. Hal ini dilakukan untuk dapat memberikan dukungan terhadap pembelajaran pendidikan jasmani yang dilakukan secara online.

\section{METODE}

Pendekatan yang digunakan dalam penelitian survei efektivitas pembelajaran teknik start jongkok pada materi lari sprint secara online kelas V SDN gayam II adalah pendekatan kualitatif. pendekatan kualitatif adalah sebuah pendekatan penelitian yang berusaha mendeskripsikan dan memahami suatu fenomena secara mendalam dengan penelitian sebagai instrumen utama (Fraenkel et al., 2012). Sebuah penelitian yang dilakukan untuk memahami suatu fenomena secara mendalam dengan peneliti sebagai instrumen utama yang di lakukan untuk menggambarkan gejala, fenomena, atau peristiwa tertentu. Pengumpulan data dilakukan untuk mendapat informasi terkait dengan fenomena kondisi, atau vareabel tertentu dan tidak dimaksudkan untuk melakukan pengujian hipotesis (Sugiyono, 2017).

Sumber data primer adalah seluruh hasil wawancara dengan guru pendidikan jasmani, peserta didik, dan orang tua serta hasil observasi langsung ke lapangan sekaligus pengamatan yang dilakukan oleh peneliti, dan kemudian peneliti mengamati teknik start jongkok pada materi lari sprint yang dilakukan secara online. Untuk mendapatkan data yang valid dan relevan, pada penelitian ini melakukan wawancara, obrsevasi, dan dokumentasi dengan datang langsung ke sekolah di SDN Gayam II dan ke rumah peserta didik. Setelah itu dianalisis oleh peneliti menggunakan norma yang sudah ada di buku panduan materi lari sprint teknik start jongkok.

Bila jawaban yang di wawancarai setelah dianalilis terasa belum memuaskan, maka peneliti akan melanjutkan pertanyaan lagi, sampai tahap tertentu, sehingga akan diperoleh data yang dianggap kredibel. Sedangkan model analisis yang digunakan adalah analisis model Miles dan Huberman bahwa aktivitas dalam analisi data kualitaif dilakukan secara interaktif dan berlangsung secara terus-menerus sampai tuntas, sehingga datanya sudah jenuh (Sugiyono, 2015). Proses analisis adalah sebagai 
berikut: 1) reduksi data, data yang telah direduksi akan memberikan gambaran yang lebih jelas, dan mempermudah peneliti untuk melakukan pengumpulan data selanjutnya, dan mencari bila diperlukan; 2) penyajian data, penyajian data bisa dilakukan dalam bentuk uraian singkat, bagan, hubungan antar kategori, flowchart, dan sejenisnya; 3) penarikan kesimpulan, dalam penelitian kualitatif dapat menjawab rumusan masalah yang dirumuskan sejak awal, tetapi juga tidak, karena seperti dikemukakan bahwa masalah dan rumusan masalah dalam penelitian kualitatif masih bersifat sementara dan akan berkembang setelah peneliti berada di lapangan (Sugiyono, 2017).

\section{HASIL}

Penelitian dilakukan dari tanggal 6 Februari 2021 sampai 6 Maret 2021 di SDN Gayam II Kecamatan Gayam kabupaten Sumenep dan kemudian dilanjutkan sesi wawancara terhadap guru penjas dan peserta didik di sekolah dan orang tua peserta didik di rumah masing-masing. yang sudah dilakukanya serangkaian penelitian dimulai dari saat observasi dan penelitian. Banyak sekali hal baru yang saya dapatkan dari hasil pengamatan dan wawancara yang saya lakukan tentang teknik start jongkok pada materi lari sprint secara online di SDN Gayam II.

\section{Wawancara yang saya lakukan dengan guru pendidikan jasmani}

Menyatakan bahwa proses pembelajaran olahraga dilakukan secara online melalu aplikasi WhatssApp guru sudah mempunyai nomer handphone (HP) orang tua masing masing peserta didik dengan konsep pembelajaran yang sudah dipertimbangkan dan direncanakan dengan cukup baik, seperti RPP terkait jadwal pembelajaran online ada karena sudah di buat oleh sekolah, cara penyampaian pembelajaran online dan media pembelajaran yang digunakan selama online. Proses pembelajaran online di SDN Gayam II Kecamatan Gayam Kabupaten Sumenep kerangka konseptual yang melukiskan prosedur sistematis dalam mengorganisasikan pengalaman belajar untuk mencapai tujuan belajar tertentu, dan berfungsi sebagai pedoman bagi perancangan pembelajaran dan para pegajar dalam merencanakan aktivitas belajar mengajar. Penyampain materi teknik start 
jongkok pada materi lari sprint di SDN Gayam II di kirim melalui whatssapp group yang sebelumnya sudah dipersiapkan oleh guru pendidikan jasmani. Media pembelajaran yang digunakan pada pembelajaran online di sekolah dasar khusunya di SDN Gayam II seperti gambar atau video yang dikirim dalam grup whatssapp dengan tujuan agar peserta didik lebih mudah memahami terkait materi yang disampaikan oleh guru. Setelah pembelajaran berakhir, guru melakukan evaluasi pembelajaran. Kegiatan evaluasi ini untuk mengetahui tingkat kemajuan belajar peserta didik dan untuk mengetahui tingkat keberhasilan guru dalam mengajar dengan indikator yang sudah ditetapkan sebelumnya, sehingga evaluasi pembelajaran ini dapat dijadikan sebagai dasar dalam penentuan pembelajaran selanjutnya. Kegiatan evaluasi yang dilakukan meliputi evaluasi kognitif dan psikomotor. Menurut pemaparan guru pendidikan jasmani SDN Gayam II, evaluasi kognitif peserta didik dengan cara mengirimkan foto dan video praktek materi melakukan start jongkok pada materi lari sprint secara online yang dikirim lewat whatsapp pribadi. Evaluasi akan efektif dilakukan dengan cara memberikan deadline atau batas akhir pengumpulan tugas yang harus dikumpulkan peserta didik. Sedangkan evaluasi psikomotrik dilakukan dengan melihat nilai dari tugas yang sudah dikumpulkan peserta didik lewat whatssapp.

"Proses pembelajaran online masih kurang efektif karena terdapat beberapa kekurangan dan keterbatasan. Pada dasarnya pembelajaran online membutuhkan akses jaringan yang baik dan memadai. Sementara itu, SDN Gayam II merupakan salah satu Sekolah Dasar yang berada di Pulau Sepudi dengan jangkauan jaringan yang terbilang cukup sulit, tapi masih bisa melakukan proses pembelajaran online. Selain itu keterbatasan lainnya adalah tidak semua orang tua peserta didik memiliki Handphone (HP) sehingga mereka, masih perlu meminjam kepada saudara atau temannya. Untuk mengatasi kendala ini guru menghubungi teman sekelas mengingatkan peserta didik supaya mengikuti pembelajaran online menghubungi langsung guru pendidikan jasmani".

Proses pembelajaran online masih kurang efektif karena terdapat beberapa kekurangan dan keterbatasan jaringan internet yang kurang bagus dan ada sebagian peserta didik yang belom mempunyai Handphone (HP). Dengan metode pembalajaran online seperti ini, diharapkan peserta 
didik harus lebih aktif lagi, karena keaktifan peserta didik menentukan tingkat efektivitas terkait metode pembelajaran dan materi yang diberikan oleh guru.

\section{Wawancara kepada peserta didik}

Sebelum pembalajaran di mulai peserta didik sudah menyiapkan buku pembelajaran di rumah untuk mengikuti pembalajaran online, untuk metode yang digunaka guru penjaskersek SDN Gayam II pada pebelajaran online melalui aplikasi whatsapp chat di grup kelas $\mathrm{V}$ dan jadwal kelas sudah di kirim guru lewat whatsApp group oleh guru pendidikan jasmani. Guru pendidikan jasmani di SDN Gayam II menyampaikan materi melalui whatssApp grup untuk pengumpulan tugas di foto peserta didik meperaktekkan teknik start jongkok dengan benar pada materi lari sprint secara online yang di sampaikan guru. Media yang di gunakan guru pendidikan jasmani di SDN Gayam II pada pembelajaran online mennggunakan video, foto, dan buku paket sekolah. Untuk menggunakan media seperti aplikasi zoom dan google clasroom belum bisa di gunakan dikarenakan akses jaringangan yang kurang bagus. Perekonomian disekitar SDN Gayam II ini dapat dikatakan menengah ke bawah pasalnya ada peserta didik yang tidak memiliki HP (handphone). Dan mereka harus meminjam milik orang tua atau kerabat dekatnya, terkadang ada peserta didik yang harus mengumpulkan tugas keesokan harinya karena $\mathrm{hp}$ tersebut digunakan. Masalah sinyal kurang bagus tapi bisa digunakan proses pembelajaran online dan peserta didik kekurangan paket internet karena belum ada paket gratis dari sekolah dan harus membeli sendiri.

"Untuk mengataisi kendala peserta didik bisa mengunakan wifi tetangga dan juga bisa kebalai desa. Pembelajaran online ini di SDN GAYAM II kurang efektif karena ada beberapa kendala ada peserta didik yang belum mempunyai $\mathrm{hp}$, banyak peserta didik malas mengikuti pembelajaran online dan sinyal di Kepulauan Sapudi kurang baik sehingga benyak peserta didik yang lambat mengumpulkan tugas tentang pembalajaran teknik start jongkok pada materi lari sprint secara online".

Wawancara kepada wali murid

Dari sekolah sudah diumumkan untuk pembelajaran online di lakukan menggunakan aplikasi whatsaap (WA) jadwal pelajaran juga di bagikan 
lewat whatsaap (WA) grup kelas jadi di grup terdiri dari guru oang tua dan anak masing masing mata pelajaran ada grup whatsaap (WA) seperti mata pelajaran PJOK pendidikan jasmani olahraga kesehatan dan lain lain, peran orang tua pada proses pembalajaran online itu harus karena sangat bersangkutan untuk membantu dan mengawasi anaknya ketika mengerjakan tugas atau melaksanakan peraktek yang di sampaikan oleh guru di sekolah untuk membantu anak kami mengikuti proses pembelajaran online, bedanya pembelajaran online itu pembalajaran di rumah dengan orang tua. Kendala sinyal dan keterbatasan alat keomunikasi handphone (HP) karena di kepulawan sepudi masih banyak masyarakat yang perekonomiannya menengah kebawah jadi kendala yang di alami wali murid seperti tidak mempunyai handphone (HP) android, kehabisan kuota internet, dan sinyal kurang bagus. Untuk mengatasi kendala kami berkordinasi dengan guru mata pelajaran bahwa misalnya untuk, pengumpulan tugas onlinenya itu tidak di lakukan pada jam mata pelajaran bisa di laksanakan satu hari full jadi kami siwa dan orang tua bisa mengrimkan sesuai dengan kedala sinyal yang ada misal pengiriman jam 7 tugas itu di berikan bukan jam 7 juga tugas itu di kumpulan jadi kami menunggu sinyal yang bagus untuk pengumpumpulan tapi di dalam satu hari itu tugas terkumpulan lewat online.

Peran orang tua sangatlah penting disini, orang tua harus bisa mengawasi dan memperhatikan putra-putrinya dalam mengukuti proses pembelajaran secara online.

"mendampingi anak kami untuk memperaktekkan teknik start jongkok supaya anak kami tidak mengalami cedera ketika melakukan praktek dalam hal pembelajaran di rumah, kami juga memotivasi anak kami untuk segera mengerjakan tugasnya agar bisa dikumpulkan tepat waktu".

Berdasarkan hal tersebut, orang tua berharap meskipun pembelajaran dilakukan secara online, tetapi harapan untuk pembelajaran tatap muka juga sangat dinanti oleh orang tua. Hal itu tidak hanya terjadi pada jenjang pendidikan dasar dan menengah, pada pendidikam timggi pun demikian, mahasiswa lebih menginginkan pembelajaran tatap muka (Victorian et al., 2021). Karena pada hakekatnya, pembelajaran pendidikan jasmani sangat 
penting untuk tetap diajarkan selama masa pandemi Covid-19, dengan begitu kemampuan motorik peserta didik yang digunakan untuk menunjang pertumbuhan dan perkembang anak dapat tercukupi. Soerahman, (2020), menawarkan beberapa model pembelajaran yang dapat diterapkan dalam pendidikan jasmani, salah satunya adalah kids atheltics.

\section{PEMBAHASAN}

Kebutuhan koneksi internet menjadi hal yang sangat penting dalam pelaksanaan pembalajaran online (Sari \& Sutapa, 2020) di sekolah dasar khususnya di SDN Gayam II. Namun kenyataannya pada proses pembelajaran online berlangsung guru, peserta didik dan orang tua banyak mengeluhkan jaringan yang di gunakan pada pembelajaran. Minimnya akses internet yang di alami di Kepulauan yang tinggal di Kecamatan Gayam dibilang kurang bagus untuk proses pembelajaran online. Dalam proses penbelajaran online di SDN Gayam II guru masih menggunakan aplikasi WhastsApp bagi kalangan guru, peserta didik, dan orang tua. Hal ini sependapat dengan penelitian dari (Bayu et al., 2020) yang menyebutkan bahwa awal panedemi Covid-19 guru pendidikan jasmani lebih banyak menggunakan whatsApp untuk memberikan materi pembelajaran pendidikan jasmani. Jaringan yang kurang bagus dapat menghambat proses pembelajang online beberapa peserta didik di daerah pelosok Desa Gayam yang susah dijangkau jaringan internet, sehingga harus mencari tempat yang bagus jaringan internet atau bisa juga menggunakan wifi tetannga di rumah untuk bisa mengikuti pembelajaran online. Pada proses pembelajaran online ada salah satu keluhan dari guru, peserta didik, dan orang tua peserta didik yang mendampingi dan mengawasi anaknya ketika pembelajan di rumah. Sehingga ada sebagian peserta didik harus ke sekolah dan menngunakan wifi sekolah ketika ada peserta didik yang kehabisan kouta internet.

Di lihat dari Kepulauan Sapudi di sekitar SDN Gayam II mayoritas orang tua peserta didik lebih cenderung bekerja sebagai petani dan nelayan, sehingga dengan pekerjaan wali murid tersebut sangat menyulitkan orang tua untuk membeli handphone dikarenakan pendapatan yang minim. Untuk 
peserta didik yang tidak mempunyai handphone mengambil tugas dengan datang langsung ke rumah guru. Kegiatatan pembelajaran online akan berjalan dengan lancar ketika peserta didik senantiasa mendapat pengawasan dari guru atau orang tua, pada pembelajaran online ini peran orang tua sangatlah penting untuk peserta didik lebih memahami materi (Qunito, 2020), jika ada peserta didik yang kurang paham pada materi bisa menanyakan pada orang tua. Orang tua juga dapat membantu mempraktekkan teknik star jongkok pada materi lari sprint yang diajarkan oleh guru pendidikan jasmani di SDN Gayam II secara online kepada anaknya. Tentunya orang tua peserta didik bersedia mendukung dan mengawasi anaknya pada proses pembelajaran online ini selama tidak dapat dilaksanakan untuk pembelajaran tatap muka. Meskipun begitu, ada beberapa wali murid yang pekerjaannya sebagai petani, nelayan, dan merantau, sehingga membuat peserta didik tersebut lalai dan kesulitan terhadap pembelajaran online, padahal pada proses pembelajaran online pendidikan jasmani sangat membutuhkan pengawasan orang tua ketika melakukan praktek start jongkok pada materi lari sprint. Maka dengan begitu dapat mengawasi anaknya supaya tidak cedera ataupun kelelahan saat melakukan praktek.

\section{KESIMPULAN}

Dari hasil survei efektivitas pembelajaran start jongkok pada materi lari sprint data penelitian yang sudah peneliti laksanakan pada peserta didik kelas V SDN Gayam II Kecamatan Gayam tahun ajaran 2020/2021 maka dapat ditarik kesimpulan bahwa di SDN Gayam II untuk pembelajaran online kurang efektif ada beberapa kendala yang menyebabkan terjadi kurang efektif pada saat proses pembelajaran online berlangsung, diantaranya: 1) kendala pada jaringan internet yang kurang bagus di Kepulauan Sapudi; 2) kendala perekonomian yang rendah, hal ini menyebabkan tidak semua peserta didik dan wali murid mempunyai handphone (HP) android; dan 3) ada sebagian orang tua yang tidak bisa membantu mengawasi pebelajaran online. 
Saran buat sekolah sebaiknya pada proses pembelajaran online di Kepulaan Sapudi supaya tidak benyak kendala untuk pembelajaranya di SDN Gayam II dapat dilakukan Luring adapun kebijakannya yaitu pihak guru dari wali murid kelas $\mathrm{V}$ yaitu mengadakan tatapmuka langsung dengan guru atau melakukan komonikasi tentang perkembangan anaknya selama proses pembelajaran di sekolah dengan begitu maka guru dan wali murid mampu melakukan tindakan apa yang kurang dari peserta didik tersebut sehinnga orang tua dan guru dapat menyelesaikan kendala yang menyebebkan bembelajaran online kurang efektif yang di lakukan pada pembelajaran.

\section{KONTRIBUSI PENULIS}

Author 1: Writing; Review \& Editing. Author 2: Methodology; Validating. Author 3: Software and Writing; Original Draft.

\section{DAFTAR PUSTAKA}

Barbour, M. (2010). Researching K-12 Online Learning: What Do We Know and What Should We Examine? Education Faculty Publications, 7(2), 712. https: / / digitalcommons.sacredheart.edu/ced_fac/ 153

Bayu, W. I., Waluyo, \& Victorian, A. R. (2020). Survei pelaksanaan pembelajaran pendidikan jasmani dan olahraga selama pandemi Covid19. Bravo's, 8(4), 161-167. https://doi.org/10.32682/bravos.v8i4.1748

Beldarrain, Y. (2008). Engaging the 21st century learner: An exploratory study of the relationship between interaction and achievement in the virtual high school [Capella University]. In Text (Issue July).

Daum, D. N. (2020). Thinking about Hybrid or Online Learning in Physical Education? Start Here!: Editor: Brian Mosier. In Journal of Physical Education, Recreation and Dance (Vol. 91, Issue 1, pp. 42-44). Routledge. https:/ / doi.org/10.1080/07303084.2020.1683387

Daum, D. N., \& Buschner, C. (2014). Research on teaching blended and online physical education. In Ri. E. Ferdig \& K. Kennedy (Eds.), Handbook of research on K-12 online and blended learning (pp. 201-222). ETC Press.

Fraenkel, J. R., Wallen, N. E., \& Hyun, H. (2012). How to Design and Evaluate Research in Education. McGraw-Hill Education.

Goad, T., Jones, E., Bulger, S., Daum, D., Hollett, N., \& Elliott, E. (2021). Predicting Student Success in Online Physical Education. American Journal of Distance Education, 35(1), 17-32. https://doi.org/10.1080/08923647.2020.1829254

Mustofa, M. I., Chodzirin, M., Sayekti, L., \& Fauzan, R. (2019). Formulasi 
Model Perkuliahan Daring Sebagai Upaya Menekan Disparitas Kualitas Perguruan Tinggi. Walisongo Journal of Information Technology, 1(2), 151-160. https://doi.org/10.21580/WJIT.2019.1.2.4067

Qunito, A. R. (2020). Parental behaviour and children's sports participation: evidence from a Danish longitudinal school study. Sport, Education and Society, 25(3), 332-347. https://doi.org/10.1080/13573322.2019.1577235

Sari, D. P., \& Sutapa, P. (2020). Efektivitas Pembelajaran Jarak Jauh dengan Daring Selama Pandemi Covid-19 Mata pelajaran Pendidikan Jasmani Olahraga dan Kesehatan (PJOK). SEMINAR NASIONAL OLAHRAGA, 2(1), 19-29. https://semnas.univpgripalembang.ac.id/index.php/semolga/article/view/84

Soerahman. (2020). Asyiknya Model Pembelajaran Kids Athletics dalam Pendidikan Jasmani dan Olahraga. Pustaka Media Guru.

Sugiyono. (2017). Metode Penelitian Pendidikan (Pendekatan Kuatitatif, Kualitatif, dan $R \& D)$. Alfabeta.

Victorian, A. R., Aryanti, S., Yusfi, H., Solahuddin, S., \& Bayu, W. I. (2021). Perspektif Calon Guru Pendidikan Jasmani Terhadap Pembelajaran Online Selama Pandemi Covid-19. JOSSAE : Journal of Sport Science and Education, 6(1), 94. https://doi.org/10.26740/jossae.v6n1.p94-106

Walton-Fisette, J. L., \& Wuest, D. A. (2015). Foundations of Physical Education, Exercise Science, and Sport. In McGraw-Hill Education (19th ed.). McGraw-Hill Education.

Williams, L., Martinasek, M., Carone, K., \& Sanders, S. (2020). High School Students' Perceptions of Traditional and Online Health and Physical Education Courses. Journal of School Health, 90(3), 234-244. https://doi.org/10.1111/josh.12865 